\title{
Cervical vertigo
}

\author{
T Brandt, A M Bronstein
}

Proprioceptive input from the neck participates in the coordination of eye, head, and body posture as well as spatial orientation. On this basis it has been argued that a syndrome of cervical vertigo might exist. However, cervical vertigo is a controversial clinical entity and patients with suspected disease often have alternative bases for their symptoms. ${ }^{1}$

The neck contains mechanisms directly involved in balance control (neck afferents), cardiovascular control (carotid bodies), and purely vascular structures (carotid and vertebral arteries). Neck movements are also invariably associated with head movements. Thus, experiencing unsteadiness or vertigo associated with neck movements could be due to a disorder in vestibular, visual, vascular, neurovascular, or cervicoproprioceptive mechanisms. Table 1 summarises the possible differential diagnoses.

Without further specification, however, the term cervical vertigo is reserved for cases where the suspected mechanism is proprioceptive. The reasoning is as follows. The perception of head rotation is mediated by vestibular, proprioceptive, or visual receptors. Vertigo should therefore be induced by stimulation of any of these systems. Degenerative or traumatic changes of the spine could induce distorted sensations of head motion (vertigo). This line of thought is, however, not as straightforward as it seems. Clearly, vestibular lesions or experimental vestibular activation (for exam- ple, a caloric test) produce powerful illusions of self motion. Similarly, visually induced illusion of self motion is readily experienced-for example, the feeling that the train we are in has started to move off when, in fact, it is the train next to ours which has done so.

Evoking a clear sensation of head turning by cervical stimulation is, by contrast, not so straight forward. To start with, to investigate neck proprioception, the head must be immobilised while the trunk is rotated. Unless this technical precaution is taken, any normal or abnormal sensations of head turning can always be due to vestibular stimulation. With this approach, under special conditions of perceptual uncertainty (for example, both the subject's head and trunk can be independently rotated in the dark), trunk rotation can induce sensations of head turning. ${ }^{2}$ However, when the subject's head is unambiguously fixed, or in normal viewing conditions, trunk rotation does not induce sensations of head turning. This is so, even in certain pathological conditions when trunk rotation is capable of inducing strong nystagmus - for example, bilateral absence of vestibular function, ${ }^{3}$ or occasionally, in cerebellar lesions. ${ }^{4}$

Questions relevant for the discussion of cervical vertigo are: What is the functional relevance of neck afferent input and how does the lack of or distortion of such input lead to vertigo or disequilibrium? Ataxia and unsteadiness occurring with sensory polyneuropathy
Neurologische Klinik,

Klinik Groshadern, Ludwig Maximilians Universitat, Munchen, Germany

T Brandt

Division of

Neuroscience and

Psychological

Medicine, Imperial

College School of

Medicine, Charing

Cross Hospital,

Fulham Palace Road,

London W6 8RF, UK

A $M$ Bronstein

Correspondence to: Dr AM Bronstein

A.Bronstein@ion.ucl.ac.uk

Received 2 October 2000 Accepted 29 November 2000
Table 1 Differential diagnosis of cervical vertigo: vertigo, unsteadiness, or oscillopsia triggered/aggravated by head-neck movements

\begin{tabular}{|c|c|}
\hline Disorder & Assumed mechanism \\
\hline \multicolumn{2}{|l|}{ Labyrinthine: } \\
\hline Benign paroxysmal positional vertigo & Canalolithiasis, cupulolithiasis \\
\hline Post-traumatic otolith vertigo & Dislodged otoconia, causing unequal heavy load on macula \\
\hline Perilymph fistula & Floating labyrinth \\
\hline \multicolumn{2}{|l|}{ Vestibular nerve: } \\
\hline Unilateral vestibular failure (eg, vestibular neuritis) & Cross coupling effects with acute vestibular tone imbalance \\
\hline Bilateral vestibular failure & Defective vestibulo-ocular reflex \\
\hline Vestibular paroxysmia & Neurovascular cross compression \\
\hline Nerve compression by cerebellopontine angle mass & Conduction block or ectopic discharges \\
\hline \multicolumn{2}{|l|}{ Ocular motor: } \\
\hline Extraocular eye muscle or gaze paresis & Inappropriate vestibulo-ocular reflex \\
\hline \multicolumn{2}{|l|}{ Central vestibular: } \\
\hline Central positional nystagmus/vertigo & Cerebellar disinhibition \\
\hline Migraine without aura & Motion sickness due to sensory hyperexcitability \\
\hline Migraine with aura (basilar migraine, vestibular migraine) & Spreading depression involving vestibular structures \\
\hline Vestibulocerebellar ataxia & Vestibulocerebellar dysfunction \\
\hline \multicolumn{2}{|l|}{ Vascular: } \\
\hline Rotational vertebral artery occlusion & Ischaemic depolarisation \\
\hline Carotid sinus syndrome & Global cerebral ischaemia \\
\hline \multicolumn{2}{|l|}{ Intoxication: } \\
\hline Positional alcohol nystagmus/vertigo & $\begin{array}{l}\text { Cerebellar and specific gravity differential between cupula } \\
\text { and endolymph (buoyancy mechanism) }\end{array}$ \\
\hline Drugs (eg, antiepileptics) & Cerebellar and ocular motor \\
\hline
\end{tabular}


are readily recognised and explained by a deficient sense of position of the lower limb joint. ${ }^{5}$ Dizziness and unsteadiness suspected to be of cervical origin could be due either to loss or inadequate stimulation of neck receptors in cervical pain syndromes. Thus far this has never been shown.

Functional relevance of neck afferents

Proprioception is mostly dependent on the deep short intervertebral neck muscles, which are extensively supplied with muscle spindles. ${ }^{67}$ The neck input participates in perceptual functions and reflex responses-namely, cervicopostural and cervico-ocular reflexes.

PERCEPTUAL FUNCTIONS

The perception of head or trunk rotation in space would be erroneous if only vestibular stimulation or only neck stimulation were involved. When vestibular and cervical stimuli are combined (head rotation relative to the trunk), the perception of both trunk and head rotation in space reflects the true position. ${ }^{28}$

Vestibular and visual cues produce postural corrections but these responses change direction with changes in head position. ${ }^{9}$ When the head is rotated horizontally by $90^{\circ}$ to the right or left-for example, horizontal head movements and horizontal retinal slip of the visual scene (right-left in head coordinates)no longer indicate lateral body sway; instead, they represent fore and aft movements. ${ }^{10}$ Consequently, the compensatory postural adjustments must be corrected and this function is also mediated by neck afferences. ${ }^{11}$

The perceived "straight ahead" and the "subjective visual vertical" can also be modified by cervical stimulation. Unilateral electrical stimulation of the neck ${ }^{12}$ causes deviation of the subjective vertical. Vibration of neck muscles, which stimulates the primary endings of the muscle spindles as if the muscle were being stretched ${ }^{13}$ elicits an illusion of head tilt and apparent movement of a visual target. ${ }^{14}$ Accordingly, subjective "straight ahead" shifts toward the side of the vibrated dorsal neck muscle. ${ }^{15}$ It has now been clarified that changes in the subjective straight ahead ${ }^{15}$ and the illusory motion of a target light during neck vibration $^{16}$ are due to minute slow phase eye movements. This vibration induced cervicoocular reflex is, in agreement with head/trunk rotation studies, ${ }^{3}$ significantly enhanced in patients with bilateral absence of vestibular function. ${ }^{16}$ In unilateral vestibular lesions, the increase in muscle spindle input (as tested by vibration) is asymmetric, restricted to the affected side, and gradually builds up over weeks. ${ }^{15}$ Of note, however, both visual illusions and postural responses are comparatively stronger than any illusion of head movement. It would seem that neck input is important for the generation of automatic reflexes but less important for generating conscious perceptions of head turning.

REFLEX RESPONSES

Two reflexes are mediated by neck proprioceptors: the postural neck reflexes and the cervico- ocular reflex. Tonic neck reflexes, studied by Magnus, ${ }^{17}$ innervate limb muscles asymmetrically. In humans, tonic postural neck reflexes can be elicited only in the newborn ${ }^{18}{ }^{19}$ - for example, ipsilateral flexion and contralateral extension of the limbs with head rotation ("fencing posture"). Neck input not only modulates body posture, but also stabilises the head with respect to the trunk by cervicocollic reflexes, interacting with vestibulocollic reflexes which stabilise the head in space. ${ }^{20}{ }^{21} \mathrm{In}$ healthy human beings, neck reflexes form a part of the multisensory intersegmental postural control mechanism thus making it virtually impossible for the clinician to carry out a selective test of neck function by simple postural manoeuvres.

It was Bárány ${ }^{22}$ who first demonstrated tonic cervico-ocular reactions in rabbits, elicited by motion of the trunk relative to the head. In humans, this tonic neck-eye reflex can only be seen in the newborn ${ }^{18}$ or in rare patients with gross CNS lesions. ${ }^{23}$ Bikeles and Ruttin ${ }^{24}$ were the first to report nystagmus during head rotation in patients with complete vestibular loss, which they ascribed to sensory input from neck joints. More recent studies of the cervicoocular reflex, elicited by rotating the trunk about the stationary head, have shown that this reflex is weak in normal subjects. ${ }^{3}$ A low velocity nystagmus, however, can be elicited in some normal subjects. ${ }^{3526}$ This reflex is adaptively enhanced in acquired vestibular loss, thereby partially substituting the vestibulo-ocular reflex deficit in the monkey ${ }^{27}$ and in humans. ${ }^{328-30}$ Thus, attempts to define cervical vertigo on the basis of cervical nystagmus ${ }^{31}$ are impractical: cervical nystagmus occurs in healthy subjects and can be particularly strong in patients with no cervical vertigo. ${ }^{34}$

\section{Experimental cervical vertigo}

In animals, transverse section of suboccipital muscles, surgical deafferentation of C1-C3, or suboccipital anaesthesia results in locomotor ataxia. ${ }^{32-35}$ Local anaesthesia of deep posterolateral neck tissue in humans ${ }^{35}{ }^{36}$ usually elicits a transiently increased ipsilateral and decreased contralateral extensor muscle tone with a tendency to fall, gait deviation, and pastpointing towards the injected side. Dieterich et $a l^{37}$ confirmed this in patients with cervicogenic headache investigated before and after bilateral therapeutic anaesthetic C2 blockades; however, they found no specific abnormality with static posturography, or subjective visual vertical or routine electronystagmography. The weak horizontal spontaneous nystagmus, directed away from the injected side as seen by Barré, ${ }^{36}$ is not a typical feature in humans. ${ }^{35} 37$ Biemond $^{38}$ reported positional nystagmus due to upper cervical root section in the rabbit but Cohen $^{39}$ showed that this positional nystagmus is species specific: most pronounced in rabbits, less in the cat, and subtle in the rhesus monkey. Positional nystagmus cannot be attributed to a disturbance of the cervical sympathetic chain ${ }^{36}$; animal experiments $s^{35}$ indicate that it most probably represents a tone imbalance of upper cervical roots. 
Clinical evidence for cervical vertigo? Because section or anaesthesia of cervical roots or muscles causes an asymmetry in somatosensory input, unilateral irritation or deficit of neck afferents could create a cervical tone imbalance, thus disturbing integration of vestibular and neck inputs. However, it has not been shown that whiplash injuries or cervical pain syndromes produce such a tone imbalance with ataxia and vertigo. Rotational vertigo and nystagmus associated with pain arising from the cervical spine with tenderness and limitation of neck movement should not be called cervical vertigo; indeed, when post-traumatic, vertebral artery dissection should be ruled out. $^{41}$

Symptoms of cervical vertigo, if it exists, would be a sensation of lightheadedness or floating unsteadiness and slight ataxia of stance and gait, perhaps more on head turns. This can be inferred from the experimental unsteadiness induced in humans by unilateral suboccipital local anaesthesia. ${ }^{35}$ As somatosensory cervical input converges with vestibular input to mediate multisensory control of orientation, gaze in space, and posture, the clinical syndrome of cervical vertigo could theoretically include perceptual symptoms of disorientation, postural imbalance, and ocular motor signs although the last looks particularly unlikely. Consequently, further clinical studies seeking to define cervical vertigo should focus on establishing reliable measures for it. These could include psychophysics, oculography, posturography, and measurements of cervicospinal reflexes but, as assessment under static conditions has so far proved inconclusive, further investigations should focus on dynamic somatosensory studies. If vestibular function is tested by vestibular stimuli and visual function by visual stimuli, then somatosensory cervical function should be tested with selective somatosensory stimulation. Complains of vertigo or unsteadiness on turning the head are much more likely to imply vestibular rather that cervical dysfunction.

Some of the more conscientious studies have been based on posturography data. ${ }^{42-45}$ Patients with chronic cervicobrachial pain (not selected for complaints of vertigo) had poorer postural control, based on vibration induced and galvanically induced body sway, than normal controls. ${ }^{42}$ It was also noted that physiotherapy was of value in reducing neck pain as well as dizziness and postural balance. ${ }^{44}$ The findings, however, are not specific enough to establish a diagnosis of cervical vertigo.

\section{Hypothetical mechanisms}

Firstly, it is not known how traumatic, degenerative, inflammatory, or rheumatic diseases affect neck sensory input. In such uncharted regions, various hypotheses thrivefor example, the hypothesis of cervical vertigo after whiplash injury. Suggestions have included neuromuscular ${ }^{46}$ and neurovascular mechanisms ${ }^{47}$ and mechanical obstruction of the vertebral artery. ${ }^{48}$ Longet $^{32}$ very early made the incidential finding that post-traumatic vertigo and ataxia improve with the use of a neck collar. ${ }^{49}$ But head trauma and whiplash injury affect not only neck structures. Whiplash injuries often damage the brain, ${ }^{50} 51$ making the interpretation of abnormal vestibulo-ocular tests difficult..$^{253}$ The otoliths are highly vulnerable to accelerations; damage to them may cause otolith vertigo, ${ }^{54}$ characterised by a benign course similar to that of neck pain. In addition, dislodged otoconia often also enter the lumen of the semicircular canals, resulting in canal lithiasis and post-traumatic benign paroxysmal positional vertigo (BPPV). ${ }^{55}$ It must be borne in mind that canal lithiasis can involve not only the posterior canal ("classic" BPPV) but also the horizontal and anterior canals, thus explaining atypical presentations which would have been previously confused with cervical vertigo or nystagmus.

A convincing mechanism of cervical vertigo would have to be based on altered upper cervical somatosensory input associated with neck tenderness and limitation of movement. Interstitial inflammatory mediators have been postulated to sensitise muscle spindles, ${ }^{56}$ and myofascial trigger points exhibit spontaneous EMG activity, which is compatible with hyperactive muscle spindles. ${ }^{57}$ If the firing characteristics (symmetric or asymmetric) of the cervical somatosensors change due to neck pain, a sensory mismatch between vestibular and cervical inputs would be expected to result in cervical vertigo. Particularly, this would occur during active head movements, when expected and actual reafferent input would not match.

\section{Differential diagnosis}

Differential diagnosis of vertigo associated with cervical symptoms or head-neck movement avoidance is broad (table 1). If it is posttraumatic or follows cervical whiplash injuries, then post-traumatic otolith vertigo, ${ }^{54}$ or benign paroxysmal positioning vertigo, ${ }^{58}$ central vestibular dysfunction secondary to brainstem concussion, vertebral artery dissection, and perilymph fistulas should be considered. ${ }^{55} \mathrm{In}$ non-traumatic cases, psychogenic vertigo ${ }^{59} 60$ can have similar symptomatology but cerebellar or spinal ataxia, vestibular paroxysmia, ${ }^{61}$ and bilateral vestibulopathy ${ }^{62}{ }^{63}$ should be considered first, before psychogenic or cervical origin is assumed. Not uncommonly, cervical pain is actually secondary to a genuine vestibular disorder, such as vestibular neuritis, and probably develops as patients stiffen up their neck muscles to avoid head movements. This feature is well recognised by physiotherpapists working with vestibular patients. ${ }^{64}$ Lesions of the extracranial portion of the vertebral arteries, as it travels the cervical column within the transverse foramina (portion V2) and loops from C2 into the foramen magnum (portion V3), have to be considered in the differential diagnosis. As this part of the vertebral artery is relatively free from atherosclerosis, occlusions due to neck movements/positions, neck manipulations, osteophyte compression, trauma, and "spontaneous" dissection can occur. ${ }^{65}$ More widespread posterior circulation features should be the norm but some cases with fairly selective vestibular symptoms have been well 
documented. ${ }^{66}$ By contrast, there seems to be no scientific basis for the syndrome of cervicalsympathetic irritation. ${ }^{36}$ It is likely that most cases of this syndrome are pure vestibular disease, vertebral artery compression, vestibular parxysmia, or basilar migraine.

In summary, vertigo can be accompanied by cervical pain, associated with head injury, whiplash injury, or cervical spine disease. In some cases it can improve dramatically with physiotherapy. None of these instances provides convincing evidence of a cervical mechanism, and alternative explanations are almost always possible. All clinical studies on cervical vertigo to date have three weak points: (1) the inability to confirm the diagnosis, (2) the lack of a specific laboratory test, and (3) the unexplained discrepancy between patients with severe neck pain without vertigo and patients complaining of disabling vertigo with moderate neck pain. If cervical vertigo exists, appropriate management is the same as that for the cervical pain syndrome, and this management should not be denied any patient. As such therapy is carried out in any case, the debate on the relevance and mechanism of cervical vertigo is more of theoretical interest than of practical relevance.

1 Brandt T. Cervical vertigo: reality or fiction?. Audiol Neurootol 1996;1:187-96.

2 Mergner T, Siebold C, Schweigart G, et al. Human perception of horizontal trunk and head rotation in space during vestibular and neck stimulation. Exp Brain Res 1991;85: 389-404.

3 Bronstein AM, Hood JD. The cervico-ocular reflex in normal subjects and patients with absent vestibular function. Brain Res 1986;373:399-408.

4 Bronstein AM, Hood JD. Cervical nystagmus due to loss of cerebellar inhibition on the cervico-ocular reflex: a case report. F Neurol Neurosurg Psychiatry 1985;48:128-31.

5 Bergin PS, Bronstein AM, Murray NM, et al. Body sway and vibration perception thresholds in normal aging and in patients with polyneuropathy. F Neurol Neurosurg Psychiatry 1995;58:335-40.

6 Cooper S, Daniel PM. Muscle spindles in man: their morphology in the lumbricals and the deep muscles of the neck. Brain 1963;86:563-86.

7 Richmond FJR, Bakker DA. Anatomical organization and sensory receptor content of soft tissues surrounding upper cervical vertebrae in the cat. $\mathcal{F}$ Neurophysiol $1982 ; 48: 49-61$

8 Nakamura T, Bronstein AM. The perception of head and neck angular displacement in normal and labyrinthinedefective subjects. A quantitative study using a rem
bered saccade technique. Brain 1995;118:1157-68.

9 Brandt Th, Krafczyk S, Malsbenden J. Postural imbalance with head extension: improvement by training as a model for ataxia therapy. Ann NY Acad Sci 1981:374:636-49.

10 Wolsley CJ, Sakellari V, Bronstein AM. Reorientation of visually evoked postural responses by different eye in orbit and head on trunk angular positions. Exp Brain Res 1996;111:283-8.

11 Thurrell A, Bertholon P, Bronstein AM. Reorientation of a visually evoked postural response during passive whole body rotation. Exp Brain Res 2000;133:229-32.

12 Wapner S, Werner H, Chandler KA. Experiments on sensory-tonic field theory of perception. $\mathcal{F}$ Exp Psychol 1951;42:341-45.

13 Matthews PBC. The reflex excitation of the soleus muscle of the decerebrate cat caused by vibration applied to its tendon. F Physiol 1966;184:450-72.

14 Biguer B, Donaldson IML, Hein A, et al. Neck muscle vibration modifies the representation of visual motion and direction in man. Brain 1989;111:1405-24.

15 Strupp M, Arbusow V, Dieterich M, et al. Perception and oculomotor effects of neck muscle vibration in vestibular neuritis. Ipsilateral somatosensory substitution of vestibular function. Brain 1988;12:677-85.

16 Popov KE, Lekhel H, Faldon M, et al. Visual and oculomotor responses induced by neck vibration in normal subjects and labyrinthine-defective patients. Exp Brain Res 1999; 128:343-52.

17 Magnus R. Korperstellung. Berlin: Springer, 1924.

18 Barany R. Uber einige Augen-und Halsmuskelreflexe bei Neugeborenen. Acta Otolaryngol (Stockh) 1918;97:103.

19 Gesell A. The tonic neck reflex in human infant. $\mathcal{F}$ Pediat 1938;3:455-64.

20 Peterson BW, Goldberg J, Bilotto G, et al. Cervicocollic reflex: its dynamic properties and interaction with vestibular reflexes. F Neurophysiol 1985;54:90-109.
21 Kanaya T, Gresty MA, Bronstein AM, et al. Control of the head in response to tilt of the body in normal and labyrinthine-defective human subjects. F Physiol 1995;489: 895-910

22 Barany R. Augenbewegungen, durch Thoraxbewegungen ausgelost. Zbl Physiol 1906;20:298-302.

23 De Kleyn A, Stenvers HW. Tonic neck reflexes on the eye muscles in man. Proc Kon Ned Akad Wet 1941;44:385-96.

24 Bikeles F, Ruttin E. Uber die reflektorischen kompensatorischen Augenbewegungen bei beiderseitiger Ausschaltung des N vestibularis. Neurol Zbl 1915;34:807-10.

25 Barnes GR, Forbat LN. Cervical and vestibular afferent control of oculomotor responses in man. Acta Otolaryngol (Stockh) 1979;88:79-87.

26 Swayer RN, Thurston SE, Becker KR, et al. The cervico-ocular reflex of normal human subjects in response to transient and sinusoidal trunk rotations. I Vestib Res 1994;4:245-9

27 Dichgans J, Bizzi E, Morasso P, et al. The role of vestibular and neck afferents during eye: head coordination in monkey. Brain Res 1974;71:225-32.

28 Bles W, de Jong JMBV, Rasmussens J. Postural and oculomotor signs in labyrinthine defective subjects. Acta Otolaryngol Suppl 1984;406:101-4.

29 Kasai T, Zee DS. Eye-head coordination in labyrinthinedefective human beings. Brain Res 1978;144:123-41.

30 Bronstein AM, Morland AB, Ruddock KH, et al. Recovery from bilateral vestibular failure: implications for visual and cervico-ocular function. Acta Otolaryngol Suppl 1995;520: 405-7

31 Hulse M. Die zervikalen Gleichgewichtsstorungen. Berlin: Springer, 1983.

32 Longet FA. Memoroises sur les troubles qui surviennent dans l'equilibration, la station et al locomotion des animaux apres la section des parties molles de la nuque. Gazette Médicale de Paris 1845;13:565-7.

33 Igarashi $\mathrm{M}$, Miyata $\mathrm{H}$, Alford $\mathrm{BR}$, et al. Nystagmus after experimental cervical lesions. Laryngoscope 1972;82:160921 .

34 Manzoni D, Pompeiano O, Stampacchia G. Cervical control of posture and movements. Brain Res 1979;169:615-19.

35 De Jong PTVM, de Jong JMBV, Cohen B, et al. Ataxia and nystagmus induced by injection of local anesthetics in the neck. Ann Neurol 1977;1:240-6.

36 Barre JA. Sur une syndrome sympathique cervical posterieur et sa cause frequent: l'arthrite cervicale. Rev Neurol 1926;45:1246-53.

37 Dieterich M, Pollmann W, Pfaffenrath V. Cervicogenic headache: electronystagmography, perception of verticality and posturography in patients before and after $\mathrm{C}_{2}^{-}$ blockade. Cephalalgia 1993;13:285-8.

38 Biemond A. On a new form of experimental position nystagmus in the rabbit and its clinical value. Proc Kon Ned Akad Wet 1939;42:370-5.

39 Cohen LA. Role of eye and neck proprioceptive mechanisms in body orientation and motor coordination. $7 \mathrm{Neu}$ rophysiol 1961;24:1-11.

40 Biemond A, de Jong JMBV. On cervical nystagmus and related disorders. Brain 1969;92:437-58.

41 Strome SE, Hartshorn DO, Carroll WR, et al. Otologic manifestations of vertebral artery dissection. Otolaryngol Head Neck Surg 1997;116:262-4.

42 Karlberg M, Persson L, Magnusson M. Reduced postural control in patients with chronic cervicobrachial pain syndrome. Gait Posture 1995;3:241-9.

43 Karlberg M. Johansson R, Magnusson M, et al. Dizziness of suspected cervical origin distinguished by posturographic
assessment of human postural dynamics. $\mathscr{f}$ Vestib Res 1996; 6:37-47.

44 Karlberg M, Magnusson M, Malmstrom EM, et al. Postural and symptomatic improvements after physiotherapy in patients with dizziness of suspected cervical origin. Arch Phys Med Rehabil 1996;77:874-82.

45 Alund M, Ledin T, Odkvist L, et al. Dynamic posturography among patients with common neck disorders. 7 Vest Res 1993;3:383-9.

46 Gray LP. Extra-labyrinthine vertigo due to cervical muscle lesions. F Laryngol 1956;70:353-61.

47 Hyslop G, Intra-cranial circulatory complications of injuries of the neck. Bull NY Acad Med 1952;28:729-33.

48 Compare WE. Electronystagmographic findings in patients with "whiplash injuries". Laryngoscope 1968;78:1226-33.

49 Hinoki M, Hine, Kada Y. Neurological studies on vertigo due to whiplash injury. Equilibrium Research 1971; (suppl 1):5-29.

50 Ommaya AK, Faas F, Yarnell P. Whiplash injury and brain damage. FAMA 1968;204:285-9.

51 Torres F, Shapiro SK. Electroencephalograms in whiplash injuries. Arch Neurol 1961;5:28-35.

52 Rubin W. Whiplash with vestibular involvement. Arch Otolaryngol 1973;97:85-7.

53 Toglia JU. Acute flexion-extension injury of the neck. Neurology 1976;26:808-814.

54 Gresty MA, Bronstein AM, Brandt Th, et al. Neurology of otolith function: peripheral and central disorders. Brain 1992;155:647-73.

55 Brandt T. Vertigo. Its multisensory syndromes. London: Springer-Verlag, 1999.

56 Johansson H, Sojka P. Pathophysiological mechanisms involved in the genesis and spread of muscular tension in occupational muscle pain and in chronic musculoskeletal pain syndromes: a hypothesis. Med Hypotheses 1991;35: pain syna 
57 Hubbard DR, Berkoff GM. Myofascial trigger points shown spontaneous needle EMG activity. Spine 1993;18:1803-7. 58 spontaneous needle EMG activity. Spine 1993;18:1803-7. vertigo: recognition and treatment. BMF 1995:311:489-91. Brandt Th, Huppert D, Dieterich M. Phobic postura vertigo: a first follow up. $\mathcal{F}$ Neurol 1994;241:191-5.

60 Furman JM, Jacob RG. Psychiatric dizziness. Neurology 1997;48:1161-6.

61 Brandt Th, Dieterich M. Vestibular paroxysmia: vascula compression of the eighth nerve? Lancet 1994;i:798-9.

62 Brandt T. Bilateral vestibulopathy revisited. Eur F Med Res 1996;1:361-8.
63 Rinne T, Bronstein AM, Rudge P, et al. Bilateral loss of vestibular function: clinical findings in 53 patients. 7 Neurol tibular function:

64 Shumway-Cook A, Horak FB, Yardley L, et al. Rehabilitation of balance disorders in patients with vestibular pathology.In: Bronstein AM, Brandt T, Woollacott $\mathrm{MH}$ eds. Balance posture and gait. London: Arnold, 1996.

65 Caplan LR. Posterior circulation disease: clinical findings, diagnosis, and management. Cambridge, MA: Blackwell, 1996. 66 Strupp M, Planck JH, Arbusow V, et al. Rotational vertebral artery occlusion syndrome with vertigo due to labyrinthine excitation. Neurology 2000;54:1376-9.

\title{
Narrative Based Medicine, An Interdisciplinary Conference
}

\author{
Research, Narrative, and Practice
}

A two day conference-Monday 3rd and Tuesday 4th September 2001

\section{Homerton College, Cambridge, UK}

BMF Publishing Group

For full details contact: BMA/BMJ Conference Unit, Tavistock Square, London, WC1H 9JP Tel: +44 (0)20 7383 6819; fax: +44 (0)20 7383 6663; email: clyders@bma.org.uk.

www.quality.bmjpg.com 